\title{
Intraoperative Splenic Injury
}

National Cancer Institute

\section{Source}

National Cancer Institute. Intraoperative Splenic Injury. NCI Thesaurus. Code C78390.

Damage to the spleen during a surgical procedure. 